CLINICAL PRACTICE

\title{
External patient temperature control in emergency centres, trauma centres, intensive care units and operating theatres: A multi-society literature review
}

T C Hardcastle, M Stander, N Kalafatis, R E Hodgson, D Gopalan

Timothy Hardcastle, a trauma surgeon at Inkosi Albert Luthuli Central Hospital and the University of KwaZulu-Natal, Durban, South Africa, is President of the Trauma Society of South Africa and Chair: Peer Review and Professional Practice Sub-committee, Association of Surgeons of SA. Melanie Stander is an emergency medicine specialist at Tygerberg Hospital and Stellenbosch University, Parow, Cape Town, and President of the Emergency Medicine Society of SA. Nicola Kalafatis, a critical care specialist at IALCH and UKZN, is Regional Chairperson KZN - Critical Care Society of Southern Africa. Eric Hodgson is Chief Anaesthesiologist at IALCH and a Clinical Lecturer in anaesthesia at UKZN. Dean Gopalan is Chief Specialist and Head: Anaesthesiology and Critical Care, University of KwaZulu-Natal, Durban, is also a council member of the SA Society of Anaesthesia.

The paper is endorsed by the Trauma Society of SA, the Emergency Medicine Society of SA, the SA Society of Anaesthesia, the SA Society for Endoscopic Surgery, and the Association of Surgeons of SA.

Corresponding author: T C Hardcastle (timothyhar@ialch.co.za; hardcastle@ukzn.ac.za)

Here we review the available literature supporting the routine and timely use of external patient warming devices of all possible types during emergency department and peri-operative situations, including the role of best ambient temperature, and provides a best-practice statement on the need for such devices. It aims to present a guideline document endorsed by the major South African professional societies in the field of emergency and peri-operative care.

S Afr Med J 2013;103(9):609-611. DOI:10.7196/SAMJ.7327

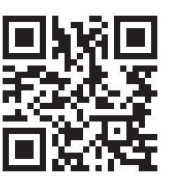

This literature review was initiated to ensure best practice in the use of external patient warming devices and appropriate ambient temperature control during emergency and peri-operative care, to prevent adverse events and increases in morbidity or mortality due to unintended hypothermia.

\section{Objective}

To provide an evidence-informed, best-practice guideline on the appropriate timing and use of external patient warming devices (all possible types) in the emergency centre and during the peri-operative care of emergency or elective trauma and surgical patients. Other relevant adjuncts may be mentioned for completeness. 


\section{Methods}

A literature search was performed reviewing existing evidence and guideline publications addressing the external or ambient maintenance of normothermia in emergency, trauma and perioperative patients undergoing resuscitation, imaging or peri-operative procedures, specifically where the risk of unintentional hypothermia exists. The literature review further examined the consequences of inadequate control of temperature in terms of physiological and septic complications, but did not aim to exhaustively review intentional therapeutic hypothermia after cardiac arrest or for severe neurological (non-traumatic) pathology.

The authors asked four questions to evaluate the content of the retrieved literature, namely:

- Which patients require warming?

- For procedures of what minimum duration is warming recommended, and what temperature should be used?

- What external devices are available, and what are their advantages and disadvantages? This includes maintenance of optimal ambient room temperatures.

- What consequences and complications occur more readily when temperature is poorly controlled, and at which human core temperatures do these complications occur?

\section{Results}

The Medline search with the Medical Subject Headings (MeSH) terms 'patient warming system' and 'peri-operative OR trauma AND hypothermia' resulted in 80 possible references. These were screened for articles that constituted research studies examining either type of device or reporting complications or consequences of hypothermia, and consensus or position statements from other international professional organisations. Twenty-seven relevant articles that addressed the topic were retrieved, and a further three articles were identified by direct reference review of the retrieved articles. Six further items were located by means of a Google Scholar search with the same search terms.

Regarding the first question, namely who should be warmed, the literature clearly demonstrates that most adult patients and all children require temperature maintenance at normothermic levels to optimise outcome. ${ }^{[1,2]}$ Patients at particular risk of hypothermia are those undergoing resuscitation in most emergency situations, especially trauma (including burns), ${ }^{[3-6]}$ those undergoing surgical procedures with combined regional/general or general anaesthesia, and those who have procedures outside the operation suite (interventional radiology or emergency department). ${ }^{[2,7-9]}$ While the role of therapeutic hypothermia in selected specific medical and surgical treatment strategies is acknowledged, it should be noted that this is not the focus of this review and that our aim is not to discourage this practice in appropriate selected patients. A recent Cochrane review of traumatic brain injury found no benefit to cooling and recommended normothermia. ${ }^{[10]}$

With regard to timing of warming device activation, there appears to be reasonable evidence supporting the use of prewarming in both adults and children for any procedure expected to last longer than 2 hours, and also for any procedure where the time of anaesthesia and surgery combined will exceed 30 minutes. Warming should also be maintained during the procedure. ${ }^{[7,11]}$ For neonates and infants ( $<1$ year of age), routine warming is recommended. All the literature suggests a peri-operative or emergency department target core body temperature of $36^{\circ} \mathrm{C}$ both pre-operatively and before discharge from the recovery room or delivery to the intensive care unit (ICU).

More recent literature also recommends that the ambient temperature in the emergency department, operation suite and
ICU to be kept at a minimum of $21^{\circ} \mathrm{C}$, and ideally around $24^{\circ} \mathrm{C}$, to ensure reduction in convective heat loss by patients, including those undergoing orthopaedic surgery. ${ }^{[2,7,11-14]}$

There appears to be little evidence from the available comparison studies that any particular external warming device has significant advantages or disadvantages over others. The recommendation is that whatever device is utilised (convective forced-air warming, warmfluid circulation blankets or carbon-fibre devices), the temperature should be adjusted to ensure a core temperature at or above $36^{\circ} \mathrm{C}$ at all times. ${ }^{[15-19]}$ Most South African health facilities currently use forcedair warming devices, as these are simple to use and cost-effective. What is clear, however, is that simply keeping patients covered with conventional fabric blankets, whether warmed or unwarmed, or foil/ plastic 'space-blankets' does not provide any warming and may not even adequately maintain the patient's temperature at application, especially in colder climates or air-conditioned hospital rooms. ${ }^{[7,1,19]}$ In addition, all fluids should ideally be administered through a fluid warming device, although this is not the focus of this review.

What is the rationale for aggressive prevention of hypothermia? The requirement for normothermia has been researched extensively over the past 15 years, and the consequences of overt or occult mild to moderate hypothermia on outcome have been well documented. These include cardiovascular consequences (myocardial ischaemia and dysrhythmias), increased inotrope requirements ${ }^{[1,1,20,20}$ and haemorrhagic consequences (clotting abnormalities, and increased transfusion requirements and intra-operative blood loss). ${ }^{[4,1,20,21]}$ All are associated with the need for longer ICU and hospital stay, thus adding to the cost of healthcare provision and justifying the minimal expense of the warming device. ${ }^{[22]}$

Furthermore, the fact that hypothermia is associated with an increased risk of surgical site sepsis as a result of a number of immunomodulatory and pathophysiological mechanisms $\mathrm{s}^{[3,1,2,2,24]}$ has been confirmed in a number of recent studies, evidence-based reviews and consensus documents. ${ }^{[12,23,25,26]}$ This holds true for elective and emergency surgery, across the spectrum from vascular to trauma and even including orthopaedic procedures (both emergency and implant related) ${ }^{[12,23,2,42,26-28]}$ and applies equally to surgery for burns. Burns patients presenting to the hospital hypothermic, despite no active cooling having been administered, and those experiencing hypothermia during excision surgery, have an increased mortality rate. ${ }^{[2,30]}$

The seminal work by Kurz et al. ${ }^{[21,28]}$ who examined the effect of mild hypothermia $\left(<36^{\circ} \mathrm{C}\right)$ in general surgical and orthopaedic operations, showed a reduced surgical site sepsis rate for normothermic patients in both groups. Subsequent studies have confirmed these findings, despite concern over increased cell shedding with forced-air warming devices in orthopaedic surgery. ${ }^{[3]]}$ Currently there appears to be little evidence that using forced-air warming devices (the most common available) increases the risk of wound and implant sepsis. ${ }^{[2,2,7323-35]}$ The important implications of increased sepsis associated with mild hypothermia are the potential need for ICU readmission, prolonged hospital stay and potential requirement for secondary procedures, all of which would increase the cost of healthcare.

The evidence overwhelmingly supports the need for liberal use of warming devices and other measures to prevent mild to moderate hypothermia.

\section{Discussion}

Hypothermia in the emergency and peri-operative patient is defined as a core temperature (measured by an indwelling central temperature catheter or tympanic measurement) of less than $36^{\circ} \mathrm{C}$. Patients with major trauma frequently arrive at the emergency centre with core temperatures below this level. This has profound effects on outcome, 
including higher rates of acute coagulopathy of trauma and higher mortality. ${ }^{[3,6,35]}$

External patient warming devices are standard of care in emergency centres throughout the world, and there are no time limits assigned to their use. There is no consensus on which type of external warming device is best. Cotton blankets and 'space' blankets do not actively warm patients, and at best maintain existing temperature and reduce heat loss somewhat. ${ }^{[19]}$ Other modalities for maintaining normothermia include removal of soaked clothes and drapes, warming of intravenous fluids, and humidification of inspired gases through the use of heat-moisture exchange filters. ${ }^{[1,36,37]}$

There is good evidence that maintaining normothermia in children and adults in the emergency centre is associated with improved outcomes and reduced morbidity, (including after head injury or other trauma, and after burns). . $3,6,35]^{[3}$

There is evidence that peri-operative prewarming, even before surgery starts, is associated with improved tolerance of both the anaesthesia and the surgical procedure. Prewarming reduces the gradient between the periphery and core, thus reducing core heat loss, which occurs through redistribution after induction of general and/or major regional anaesthesia.

Ongoing intra-operative warming in both emergency and elective surgery, irrespective of type, extent or duration, is associated with improved rates of postoperative normothermia and more rapid recovery. In addition, intra-operative normothermia significantly reduces postoperative sepsis rates and wound complications. For any procedure, warming must span the period of the surgery and of anaesthesia induction and recovery. A cost benefit for the use of patient warming devices has been demonstrated at $\geq 30$ minutes total procedural time..$^{[7,1,22]}$ Finally, the availability and use of warming devices are highly recommended in international and local expert

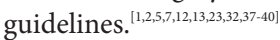

\section{Conclusion}

The consensus from South Africa and around the world, including the World Health Organization, is that normothermia is essential for optimal patient outcome during emergency care and peri-operative management, reducing both morbidity and mortality.

Recommended practices locally should therefore routinely include:

- Routine measurement of core temperature, with either intraoesophageal or tympanic temperature probes.

- The ambient temperature in the emergency department or operation room should be kept at $21^{\circ} \mathrm{C}-24^{\circ} \mathrm{C}$ by limiting cool airconditioner settings, as this is strongly associated with a reduction in septic complications.

- Active warming must be instituted for any patient with a core temperature of $<36^{\circ} \mathrm{C}$.

- Routine use of external warming devices for all emergency and peri-operative patients who do not have a high temperature at presentation is advised.

- Routine use of external warming devices for all children is advised.

- These devices should be used in association with fluid warming devices, heat-moisture exchange filters in breathing circuits, and other methods to prevent heat loss.

- If hypothermia is identified, rewarming should be undertaken.

1. American Academy of Pediatrics, Committee on Pediatric Emergency Medicine, American College of Emergency Physicians Pediatric Committee, Emergency Nurses Association Pediatric Committee Joint Policy Statement - Guidelines for Care of Children in the Emergency Department. Pediatrics 2009;124(4):1233-1243. [http://dx.doi.org/10.1542/peds.209-1807]

2. Hooper VD, Chard R, Clifford T, et al. ASPAN's Evidence-Based Clinical Practice Guideline for the Promotion of Perioperative Normothermia. J Perianesth Nurs 2010;25(6):346-357. [http://dx.doi. org/10.1016/j.jopan.2010.10.006]
3. Søriede E, Smith CE. Hypothermia in trauma victims - friend or foe? ITACCS Trauma Care Journal 2005;Winter:18-20. http://www.itaccs.com/traumacare/archive/05_01_Winter_2005/index.htm (accessed 21 December 2012)

4. Mitra B, Tullio F, Cameron PA, Fitzgerald M. Trauma patients with the 'triad of death'. Emerg Med 2012;29(8):622-625 [http://dx.doi.org/10.1136/emj.2011.113167]

5. Trauma Society of South Africa. Protocol for hypothermia management. http://www.traumasa.co.za/ library/discipline-specific-documentation (accessed 30 November 2012).

6. Frischknecht A, Lustenberger T, Bukur M, et al. Damage control in severely injured trauma patients - a tenyear experience. J Emerg Trauma Shock 2011;4(4):450-454. [http://dx.doi.org/10.4103/09474-2700.86627]

NICE Clinical Guideline 65: The management of inadvertent perioperative hypothermia in adults. Royal College of Nursing and National Institute of Clinical Exellence, April 2008. http://www.nice org.uk/guidance/cg/published/index.jsp;jsessionid=41DA9028DCD2F1269219C1A35E577F37?d 16544- $\mathrm{p}=4$ (accessed 12 December 2012

8. Jayaraman L, Sethi N, Sood J. Anaesthesia outside the operating theatre. Update in Anaesthesia 2009;25(1):37-41. http://update.anaesthesiologists.org/2009/06/01/update-in-anaesthesia-volume-25number-1-2009 (accessed 21 December 2012).

9. Abelha FJ, Castro MA, Neves AM, Landeiro NM, Santos CC. Hypothermia in a surgical intensive care unit. BMC Anesthesiol 2005;5:7. http://www.ncbinlm.nih.gov/pubmed/15938757 (accessed 6 August 2013).

10. Sydenham E, Roberts I, Alderson P. Hypothermia for traumatic head injury (Review). Cochran Database Syst Rev 2009;(2):CD001048 [http://dx.doi.org/10.1002/14651858.CD001048.pub3]

11. Putzu M, Casati A, Berti M, Pagliarini G, Fanelli G. Clinical complications, monitoring and management of perioperative mild hypothermia: Anesthesiological features. Acta Biomed 2007;78(3):163-169.

12. Hardcastle T. Surgical site infection prevention in the OR: Best practice in 2010. SA Theatre Sister 2010;35:30-32.

13. American College of Emergency Physicians. Policy Compendium 2012. Dallas, Tx: ACSP, 2012:74-78, 92. 4. Flemming E, IUSS Norms and Standards Task Team. Dept of Health-CSIR IUSS Health Facilities Guide for Emergency Centres and ICU design. Draft 1.3, March 2013. http://www.iussonline.co.za/ norms-and-standards/clinical-services/ (accessed 4 April 2013).

15. Fanelli A, Danelli G, Ghisi D, Ortu A, Moshini E, Fanelli G. The efficacy of a resistive heating underpatient blanket versus a forced-air warming system: A randomized controlled trial. Anesth Analg 2009;108(1):199-201. [http://dx.doi.org/10.2113/ane.0bo13e3181e6199]

16. Brandt $\mathrm{S}$, Oguz R, Huttner $\mathrm{H}$, et al. Resistive-polymer versus forced-air warming: Comparable efficacy in orthopedic patients. Anesth Analg 2010;110(3):834-838. [http://dx.doi.org/10.2113/ane.0b013e3181cb3f5f]

7. De Brito Poveda V, Martinez EZ, Galvao CM. Active cutaneous warming systems to preven intraoperative hypothermia: A systematic review. Rev Lat Am Enfermagem 2012;20(1):183-191. [http://dx.doi.org/10.1111/j.1365-2702.2012.04287.x]

18. Hasegawa K, Negishi C, Nakagawa F, Ozaki M. Core temperatures during major abdominal surgery in patients warmed with new circulating-water garment, forced-air warming, or carbon-fiber resistiveheating system. J Anesth 2012;26(2):168-173. [http://dx.doi.org/10.1007/s00540-011-1306-1]

19. Kimberly Clarke Roundtable Summary: Perioperative Temperature Management. New York McMahon Publishing Group, 2005.

20. Bush HL, Hydo LJ, Fischer E, Fantini GA, Silane MF, Barie PS. Hypothermia during elective abdominal aortic aneurysm repair: The high price of avoidable morbidity. J Vasc Surg 1995;21(3):392-402. [http:// dx.doi.org/10.1016/S0741-5214(95)70281-4]

21. Schmied H, Kurz A, Sessler D, Kozek S, Reiter A. Mild hypothermia increases blood loss an transfusion requirements during total hip arthroplasty. Lancet 1996;347(8997):289-292. [http://dx.doi. org/10.1016/S0140-6736(96)90466-3]

22. Wagner VD. Patient safety first: Unplanned perioperative hypothermia. AORN J 2006;83(2):470-476.

23. NICE Guideline 74. Surgical Site Infection. National Institute for Clinical Excellence, October 2008. http://www.nice.org.uk/guidance/cg/published/index.jsp;jsessionid=41DA9028DCD2F1269219C1A3 5E577F37?d-16544-p=5 (accessed 21 November 2012).

24. World Alliance for Patient Safety. World Health Organisation Guidelines for Safe Surgery, 2009. Geneva: WHO 2009:69-74.

25. Melling AC. Warming patients before clean surgery reduced the incidence of postoperative wound infection. Evid Based Nurs 2002;5:48. [http://dx.doi.org/10.1136/ebn.5.2.48]

26. Sharp RI., Chesworth T, Fern ED. Do warming blankets increase bacterial counts in the operatin field in a laminar-flow theatre? J Bone Joint Surg $[\mathrm{Br}]$ 2002;84-B(4):486-488. [http://dx.doi org/10.1302/0301-620X.84B4.11974]

27. Sessler, DI, Olmsted, RN, Kuelpmann R. Forced-air warming does not worsen air quality in laminar flow operating rooms. Anesth Analg 2011;113(6):1416-1421. [http://dx.doi.org/10.1213/ ane. $0 \mathrm{~b} 013 \mathrm{e} 318230 \mathrm{~b} 3 \mathrm{cc}$

28. Kurz A, Sessler D, Lenhardt R, for the Study of Wound Infection and Temperature Group. Perioperative normothermia to reduce the incidence of surgical-wound infection and shorten hospitalization N Engl J Med 1996;334(19):1209-1215. [http://dx.doi.org/10.1056/NEJM199605093341901]

29. Corallo JP, King B, Pizano LR, Namias N, Schulman CI. Core rewarming of a burn patient during excision to prevent hypothermia. Burns Incl Therm Inj 2008;34(3):418-420.

30. Singer AJ, Taira BR, Thode HC, et al. The association between hypothermia, prehospital cooling and mortality in burn victims. Acad Emerg Med 2010;17(4):456-459. [http://dx.doi.org/10.1111/j.15532712.2010.00702.x]

31. Legg AJ, Cannon T, Hamer AJ. Do forced air patient-warming devices disrupt unidirectional Legg A), Cannon T, Hamer AJ. Do forced air patient-warming devices disrupt unidirectiona
downward airflow? J Bone Joint Surg Br 2012:94-B(2):254-256. [http://dx.doi.org/10.1302/0301 620X.94B2.27562]

32. Insler SR, Sessler DI. Perioperative thermoregulation and temperature monitoring. Anesthesiol Clin 2006;24(4):823-837. [http://dx.doi.org/10.1016/j.atc.2006.09.001]

33. Kurz A. Thermal care in the perioperative period. Best Pract Res Clin Anaesthesiol 2008;22(1):39-62 [http://dx.doi.org/10.1016/j.bpa.2007.10.004]

34. Torossian A. Thermal management during anaesthesia and thermoregulation standards for the prevention of inadvertent perioperative hypothermia. Best Pract Res Clin Anaesthesiol 2008;22(4):659668. [http://dx.doi.org/10.1016/j.bpa.2008.07.006]

35. Ireland S, Endacott R, Cameron P, Fitzgerald M, Paul E. The incidence and significance of accidental hypothermia in major trauma - a prospective observational study. Resuscitation 2011;82(3):300-306. [http://dx.doi.org/10.1016/j.resuscitation.2010.10.016]

36. Committee on Trauma. ATLS Student Manual. Chicago, Ill.: American College of Surgeons, 2008.

37. Institute for Healthcare Improvement. Maintain Perioperative Normothermia in Surgical Patients. http://www.ihi.org/knowledge/Pages/Changes/MaintainPeriopNormothermiaSurgicalPts.aspx http://www.ihi.org/knowledge/P

38. South African Society of Anaesthesiologists. Practical Guidelines. Southern African Journal of South African Society of Anaesthesiologists. Practical Guidelines. Southern African Journal of
Anaesthesia and Analgesia 2006;12: supplement. http://www.saja.co.za/index.php/sajaa/issue/view/11

(accessed 21 December 2012).

9. American Society of Anesthesiologists Task Force on Postanesthetic Care. Practice Guidelines for Postanesthetic Care. Anesthesiology 2002;96(3):742-752.

40. Hardcastle TC, Steyn E, Boffard KD, et al. Guideline for the assessment of trauma centres for South Africa. S Afr Med J 2011;101(3):189-194.

Accepted 2 August 2013. 